\title{
PI20-Catenin And Its Phosphorylation On Tyr228 Inhibits Proliferation And Invasion In Colon Adenocarcinoma Cells
}

This article was published in the following Dove Press journal: OncoTargets and Therapy

\author{
Xiuming Ding' \\ Xiuqin Wang ${ }^{2}$ \\ Shifen $\mathrm{Lu}^{3}$ \\ Xuemei $\mathrm{Gao}^{4}$ \\ Shumei Ju ${ }^{4}$ \\ 'Department of Intervention, Linyi \\ Central Hospital, Linyi, People's Republic \\ of China; ${ }^{2}$ Department of Dermatology, \\ The Third People's Hospital of Linyi, \\ Linyi, People's Republic of China; \\ ${ }^{3}$ Department of Gynaecology and \\ Obstetrics, The Third People's Hospital \\ of Linyi, Linyi, People's Republic of China; \\ ${ }^{4}$ Department of Paediatrics, Linyi Central \\ Hospital, Linyi, People's Republic of China
}

Correspondence: Shumei Ju Department of Paediatrics, Linyi Central Hospital, No. 17, Health Road, Yishui County, Linyi City, Shandong Province 276400, People's Republic of China Email Jushumeimdu@|26.com
Background: Colorectal cancer is the third most common malignancy worldwide and is one of the leading causes of cancer-related mortality. P120-catenin protein has been well known to exert anticancer effects in several malignant diseases. The aim of our study was to investigate the phosphorylation of p120-catenin in colon adenocarcinoma (CAC) and its association with prognosis, and its role in tumor progression.

Methods: Immunohistochemical (IHC) staining was used to explore the existence of p120-catenin and its phosphorylation on tyrosine 228 (pY228-p120-catenin) in CAC samples. Overexpression and knockdown were achieved by transient transfection into SW480 cells using Lipofectamine 3000. CCK-8 and Matrigel-transwell assays were conducted to evaluate proliferation and invasion capacities, respectively. RT-qPCR and Western blotting were performed to analyze downstream signaling pathways. Chi-square test was used to analyze correlations between p120-catenin and clinicopathological characteristics. Univariate and multivariate analyses were used to identify independent prognostic factors.

Results: Lower p120-catenin and pY228-p120-catenin levels were identified in CAC tissues and were both correlated with advanced tumor stage. Additionally, lower pY228-p120catenin indicated poorer prognosis of CAC patients although p120-catenin showed little significance. Overexpression of p120-catenin suppressed SW480 cell proliferation and invasion via stabilizing E-cadherin and inhibiting RhoA activation. Phosphorylation of Y228 on p120-catenin by Src protein enhanced the anticancer effects of p120-catenin.

Conclusion: P120-catenin and its phosphorylation on site Y228 play anticancer effects in colon adenocarcinoma via multiple signaling pathways. Hypophosphorylation of Y228 on p120-catenin in tumor tissues indicates poor clinical outcomes of colon adenocarcinoma patients.

Keywords: colon adenocarcinoma, p120-catenin, phosphorylation, prognosis, RhoA

\section{Introduction}

Colorectal cancer is the third most common malignancy worldwide and is one of the leading causes of cancer-related mortality ${ }^{1}$ The incidence of colorectal cancer is increasing especially in Asian countries ${ }^{2}$ The current therapy targeting colorectal cancer includes surgical resection, radiotherapy and chemotherapy ${ }^{3}$ The early stage patients (TNM stage I-II) are considered with good prognosis with the 5-year overall survival more than $70 \%{ }^{4}$ Although the combined treatment improved clinical outcomes during the past decades, the prognosis for late stage patients

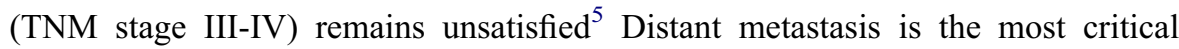


prognosis factor resulting in unfavorable prognosis, and the current chemotherapies have little effect on metastatic colorectal cancer patients ${ }^{6}$ Moreover, about $10-20 \%$ of early stage patients develop tumor recurrence or distant metastasis even underwent curative resection ${ }^{7}$ Therefore, it is important to unravel mechanisms of colorectal cancer progression and develop biomarkers to identify high-risk patients for treatment evaluation.

Cadherin and catenin family proteins play crucial roles in modulating epithelial-mesenchymal transition (EMT) process, which is a key event associated to cancer migration and invasion. ${ }^{8}$ For example, E-cadherin is recognized as a suppressor in EMT and its depletion results in tumor progression including gastric cancer, colorectal cancer, ovarian cancer, etc. ${ }^{9,10}$ P120-catenin is an armadillo catenin and is initially identified to interact with the cytoplasmic domain of E-cadherin ${ }^{11}$ The interaction between p120-catenin and E-cadherin helps stabilizing E-cadherin and enhancing the intercellular adhesion ${ }^{12}$ Besides E-cadherin, p120-catenin can interact with other components and participates in multiple cellular processes including cytoskeletal arrangement, intracellular signaling transduction, and protein transcription $^{13}$ The involvement of p120-catenin in several malignancies has been discovered in the past decades. ${ }^{14,15}$ For example, dysfunction or loss of p120-catenin expression has been identified in pancreatic cancer, esophageal cancer, prostate cancer, and lung cancer. ${ }^{16-19}$ Furthermore, low expression of p120-catenin is considered to correlate with poor cancer prognosis. However, the role of p120catenin seems different in breast cancers on that it induces cancer metastasis ${ }^{20}$ while another group reported its effect on repressing breast cancer progression ${ }^{21}$ Therefore, its detailed function seems distinct depending on cancer types.

Here in the current study, we explored the expression of p120-catenin and its phosphorylation level on site Tyrosine 228 (Tyr228 or Y228) in colon adenocarcinoma (CAC). We identified a significant decrease of p120-catenin in clinical tumor tissues, which was associated with advanced tumor stage. However, the prognostic effect of p120-catenin expression showed no statistical significance. In contrast, the phosphorylation of Tyr228 was an independent unfavorable prognostic factor according to our results. Additionally, we conducted cellular experiments by overexpressing p120-catenin and its mutants to investigate the underlying mechanisms, which confirmed the importance of Tyr228 in anticancer process. Furthermore, we identified Src protein as an upstream kinase on phosphorylating Tyr228 of p120-catenin. Our study provided evidence on the phosphorylating regulation of p120-catenin and its involvement in CAC progression.

\section{Methods}

\section{Patients And Samples}

This study was approved by the Ethics Committee of Linyi Central Hospital. Written informed consent was obtained from each patient or direct relatives. Furthermore, this study was conducted in accordance with the Declaration of Helsinki. A cohort of 104 CAC patients was retrospectively enrolled from patients who underwent primary surgical resection from June 2008 to June 2013 in our hospital. None of the patients received preoperative chemotherapy treatment and all diagnoses were based on pathological examination. Retrieved patients' information include age, gender, tumor location, tumor differentiation, tumor size (largest diameter), invasion depth (T stage), and TNM stage. We only chose the patients that survived more than 12 months after surgery to avoid extreme bias. The follow-up was completed in December 2017, with a median follow-up time of 57 months (range, 14-103 months). Overall survival (OS) was defined as the interval from the primary surgery to the date of death or the last follow-up.

\section{Immunohistochemistry (IHC) And IHC Evaluation}

IHC was performed using a standard ABC method as described by others. Briefly, embedded tissue samples were cut into 4- $\mu \mathrm{m}$ sections for deparaffinization. The slides were then undergoing antigen retrieve step, followed by treated with $3 \%$ hydrogen peroxide. After blocking the nonspecific antigens, slides were incubated with indicated antibodies (1:1000) or PBS (negative control). Sections were then counterstained with hematoxylin and analyzed independently by two pathologists.

The evaluation of IHC results was based on percentage of positive tumor cells. Positive percentage was scored as $1(0-20 \%$ positive) or $2(21-50 \%$ positive) or $3(51-75 \%$ positive) or 4 (76-100\% positive). The patients were then grouped into two subgroups based on the median IHC score. Patients with IHC score higher than 2 were grouped as high expression, while low expression was classified with IHC score no higher than 2.

\section{Antibodies And Reagents}

The anti-pY228-p120-catenin antibody was purchased from BD Bioscience (\#612537). The anti-GTP-RhoA antibody 
was purchased from NewEast (\#26904). The anti-p120-catenin (\#59854), anti-snail (\#3879), anti-c-myc (\#9402), anti-Ecadherin (\#14472), anti- $\beta$-actin (\#4970), anti-RhoA (\#2117), anti-ROCK1 (\#4035), and anti-Src (\#2109) antibodies were purchased from Cell Signaling Technology.

The full-length coding regions of human p120-catenin were cloned into pCDNA3.1 vector by Genephama (Shanghai, China), which was used for overexpressing p120-catenin in SW480 cells. The mutation of Y228F and Y228E was generated based on site-directed mutagenesis strategy by Genephama. The c-Src construct was purchased from Addgene (\#42205). All plasmid constructs were verified by DNA sequencing. Knockdown of Src was achieved by using specific siRNA from Santa Cruz Biotechnology (\#sc-29228).

\section{Cell Culture And Transfection}

The human CAC cell line SW480 was obtained from the American Type Culture Collection (Manassas, VA, USA) Cells were maintained in Dulbecco's modified Eagle's medium (DMEM) supplemented with $10 \%$ FBS and $1 \%$ penicillin $(10,000 \mathrm{U} / \mathrm{mL}) /$ streptomycin $(10 \mathrm{mg} / \mathrm{mL})$ in a humidified atmosphere at $37^{\circ} \mathrm{C}$ with $5 \% \mathrm{CO}_{2}$. Overexpression and siRNA-knockdown were performed with Lipofectamine 3000 reagent (Invitrogen, Carlsbad, CA, USA) following the manufacturer's procedure. The transfection efficiencies were verified by Western blot analyses.

\section{Real Time-Quantitative PCR (RT-qPCR)}

Total RNA was extracted from cultured cells using the TRIzol reagent (Life Technology, CA, USA) following the instructions. The cDNA template for quantitative real-time PCR was achieved by reverse transcription PCR. GAPDH was chosen as the normalization housekeeping gene. Comparative $\mathrm{Ct}$ method $(\Delta \mathrm{Ct})$ was utilized to calculate the relative mRNA levels. The RNA differences were presented as fold changes compared with control groups. The sequences of primers are shown as followings:

Snail forward, 5'-TGCTCATCTGGGACTCTGTC-3'

Snail reverse, 5'-CTCATCTGACAGGGAGGTCA-3' c-Myc forward, 5'-GCCACGTCTCCACACATCAG-3', c-Myc reverse, 5'-TCTTGGCAGCAGGATAGTCCT T-3'.

E-cadherin forward, 5'-ACAGCCCCGCCTTATGAT T-3'

E-cadherin reverse, 5'-TCGGAACCGCTTCCTTCA-3'

GAPDH forward, 5'-ACGAATTTGGCTACAGCAAC AGGG-3';
GAPDH reverse, 5'-TCTACATGGCAACTGTGAGG AGG-3'.

\section{Western Blot}

Cellular lysates were achieved by resuspending cells in NP-40 lysis buffer containing protease inhibitors and phosphatase inhibitors. Extracted proteins were resolved by $12 \%$ SDS-PAGE. PVDF membranes were used for immunoblotting. The membranes were blocked with $5 \%$ nonfat milk at room temperature for at least $1 \mathrm{hr}$ and subjected to incubation with primary antibodies at $4{ }^{\circ} \mathrm{C}$ for overnight. The membranes were then incubated with the secondary antibody at room temperature for $1 \mathrm{hr}$ on the following day. Electrogenerated chemiluminescence (ECL) imaging was finally performed with X-ray films and scanned. Data were semi-quantified using Image $\mathrm{J}$ Software and repeated for three times.

\section{Proliferation Assay}

To evaluate the effect of p120-catenin on SW480 cell proliferation, plasmid or siRNA transfected cells were seeded at $2 \times 10^{4}$ cells per well in a 96-well plate and cultured in DMEM. After culturing for 1, 2, 3, 4 days, cell proliferation was assessed by a Cell Counting Kit-8 (\#CK04-500, Dojindo, Japan) according to the manufacturer's instructions. Briefly, $10 \mu \mathrm{L}$ of CCK-8 reagent was added into each well and incubated for $4 \mathrm{hrs}$ at $37^{\circ} \mathrm{C}$. Absorbance at $450 \mathrm{~nm}$ was then measured by a microplate reader, and corresponding proliferation curves were plotted. All experiments were repeated for three times.

\section{Invasion Assay}

Invasion assays were performed using Transwell chambers (BD Biosciences, USA) pre-coated with of Matrigel (Becton Dickinson, San Jose, CA). Briefly, $1 \times 10^{5}$ cells were re-seeded into the upper chamber and cultured in serum-free medium after cell adhesion. 20\% fetal calf serum was added to the bottom chamber to induce cell invasion. After culturing the Matrigel-coated chambers at $37^{\circ} \mathrm{C}$ for $24 \mathrm{hrs}$, the invaded cells were observed by staining with $0.1 \%$ crystal violet for 15 mins under a light microscope. All experiments were repeated for three times.

\section{Statistical Analysis}

Statistical analyses were conducted by using the SPSS version 19.0 (IBM, New York, NY, USA). The association between the p120-catenin or pY228-p120-catenin level 
and clinical features were assessed by Chi-square test. The overall survival curves of colon cancer patients were plotted using the Kaplan-Meier analysis. Statistical analysis of independent prognostic factors was carried out with multivariate analysis model. Student's $t$-test was applied to analyze the results of cell experiments. $\mathrm{P}<0.05$ was considered statistically significant.

\section{Results}

\section{Patients Characteristics}

The clinicopathologic features of all patients enrolled in this study are shown in Table 1 . There were 55 patients $(55 / 104,52.9 \%)$ with age older than 55 years, and the other 49 patients $(49 / 104,47.1 \%)$ younger than 55 years at the time of disease diagnosis. Most patients $(75 / 104$,

Table I Correlations Between PI20-Catenin Level And Clinicopathological Characteristics

\begin{tabular}{|c|c|c|c|c|}
\hline \multirow[t]{2}{*}{ Variables } & \multirow{2}{*}{$\begin{array}{l}\text { Patients } \\
(n=104)\end{array}$} & \multicolumn{2}{|c|}{ pl20-Catenin } & \multirow[t]{2}{*}{ P Value } \\
\hline & & $\begin{array}{l}\text { High } \\
(n=56)\end{array}$ & $\begin{array}{l}\text { Low } \\
(n=48)\end{array}$ & \\
\hline \multicolumn{5}{|l|}{ Age (years) } \\
\hline$\leq 55$ & 49 & 26 & 23 & 0.880 \\
\hline$>55$ & $>55$ & $>55$ & $>55$ & \\
\hline \multicolumn{5}{|l|}{ Gender } \\
\hline Female & 29 & 16 & 13 & 0.866 \\
\hline Male & 75 & 40 & 35 & \\
\hline \multicolumn{5}{|l|}{ Location } \\
\hline Ascending & 42 & 25 & 17 & 0.603 \\
\hline Transverse & 13 & 7 & 6 & \\
\hline $\begin{array}{l}\text { Descending/ } \\
\text { sigmoid }\end{array}$ & 49 & 24 & 25 & \\
\hline \multicolumn{5}{|l|}{ Differentiation } \\
\hline Well & 16 & 8 & 8 & 0.845 \\
\hline Moderate & 80 & 43 & 37 & \\
\hline Poor & 8 & 5 & 3 & \\
\hline \multicolumn{5}{|l|}{$\begin{array}{l}\text { Tumor size } \\
\text { (diameter, cm) }\end{array}$} \\
\hline$\leq 5.0$ & 58 & 41 & 17 & $<0.001 *$ \\
\hline$>5.0$ & 46 & 15 & 31 & \\
\hline \multicolumn{5}{|l|}{ Invasion depth } \\
\hline TI-T2 & 47 & 26 & 21 & 0.784 \\
\hline T3-T4 & 57 & 30 & 27 & \\
\hline \multicolumn{5}{|l|}{ TNM stage } \\
\hline I-II & 50 & 33 & 17 & $0.017^{*}$ \\
\hline III-IV & 54 & 23 & 31 & \\
\hline
\end{tabular}

Note: *Indicates statistically significant $(\mathrm{P}<0.05)$.
$72.1 \%)$ were male and only 29 cases $(29 / 104,27.9 \%)$ were female patients. There were 42 cases $(42 / 104,40.4 \%)$ with tumor location in ascending colon, 13 patients (13/104, $12.5 \%$ ) with tumor location in transverse colon, and the other 49 patients $(49 / 104,47.1 \%)$ with tumor location in descending or sigmoid colon. Most cases (80/104, 76.9\%) were classified as moderate pathological differentiation, only 16 cases $(16 / 104,15.4 \%)$ with well differentiation and $8(8 / 104,7.7 \%)$ cases with poor tumor differentiation. Forty-six cases $(46 / 104,44.2 \%)$ showed a largest tumor diameter as larger than $5.0 \mathrm{~cm}$, and the other 58 cases $(58 /$ $104,55.8 \%$ ) with smaller tumor size. The patients' T stage was evaluated based on tumor invasion depth. Accordingly, 47 cases (47/104, 45.2\%) were grouped into T1-T2 stages, while the other 57 cases $(57 / 104,54.8 \%)$ as T3-T4 stages. In addition, the TNM stage was also retrieved and 54 cases $(54 / 104,51.9 \%)$ were with advanced tumor stage (TNM stage III-IV).

\section{Tissue Level Of PI20-Catenin And Its Phosphorylation Level Of pY228}

The expression of p120-catenin was tested by IHC in clinical tissues (Figure 1A and B). Interestingly, low p120-catenin was correlated with larger tumor size $(\mathrm{P}<0.001)$ and advanced TNM stage ( $\mathrm{P}=0.017$, Table 1$)$, indicating its tumor-suppressing role in CAC. Similarly, the phosphorylation level of Y228 on p120-catenin (pY228-p120-catenin) was also explored by IHC (Figure $1 \mathrm{C}$ and D). The correlations between pY228-p120-catenin and patients' clinicopathological characteristics were analyzed by Chi-square test (Table 2). Accordingly, hypophosphorylation was correlated with larger tumor size $(\mathrm{P}=0.020)$ and advanced $\mathrm{T}$ stage $(\mathrm{P}=0.003)$. Moreover, patients with advanced TNM stages showed lower pY228-p120-catenin level ( $\mathrm{P}=0.048)$, implying its possible role in CAC progression.

\section{Prognostic Significance Of PI20-Catenin And Its Phosphorylation On Y228}

We next assessed the clinical significance of p120-catenin and pY228-p120-catenin by Kaplan-Meier survival test. Although the total p120-catenin level showed no significant effect on the overall survival $(\mathrm{P}=0.559$, Figure $1 \mathrm{E})$, its phosphorylation on Y228 was negatively correlated with the survival rate $(\mathrm{P}=0.005$, Figure $1 \mathrm{~F})$. Patients with higher pY228-p120-catenin level showed a longer overall survival time compared to those with lower phosphorylation level $(88.8 \pm 3.2$ vs $74.0 \pm 4.3$ months). The effect of other clinical parameters was also analyzed by univariate 
A

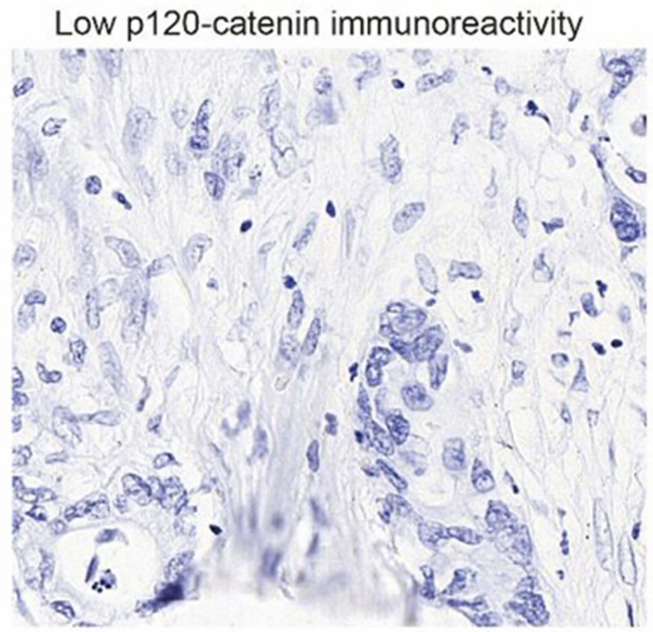

C Low pY228-p120-catenin immunoreactivity

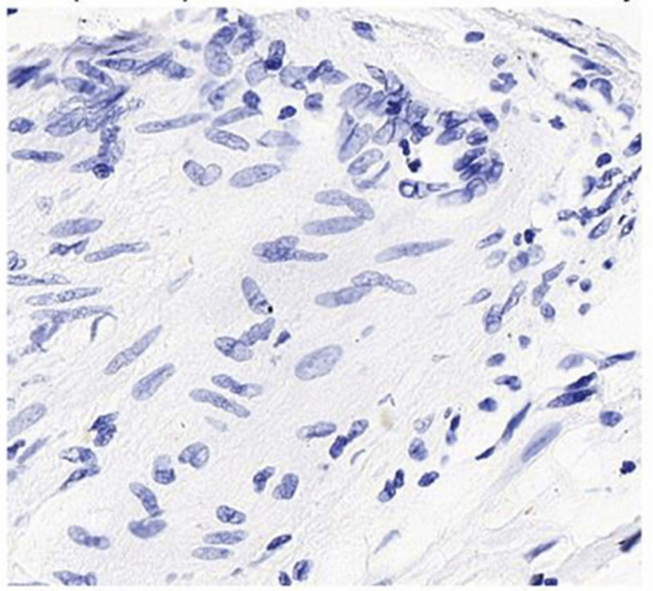

E

p120-catenin level

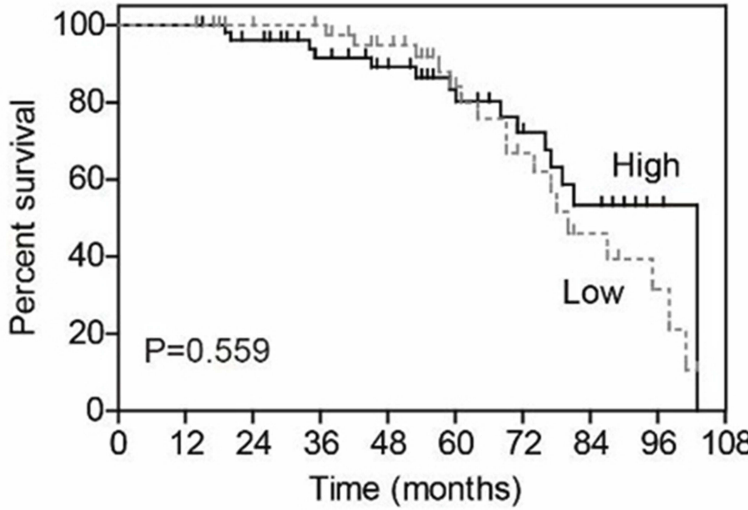

B

High p120-catenin immunoreactivity

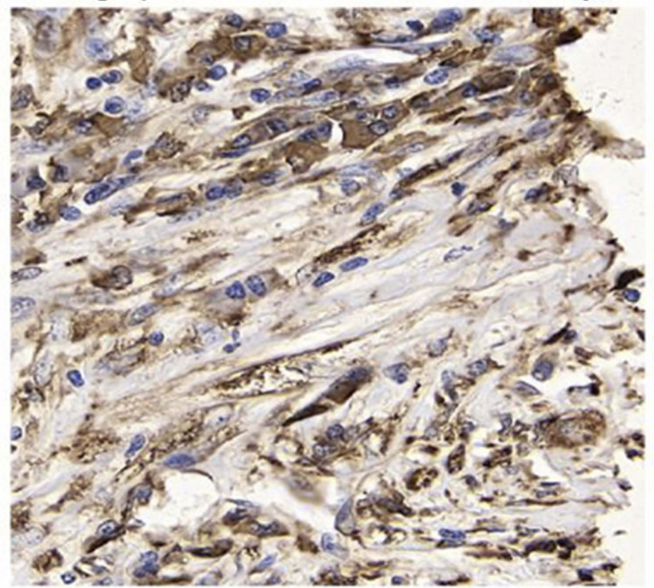

D High pY228-p120-catenin immunoreactivity

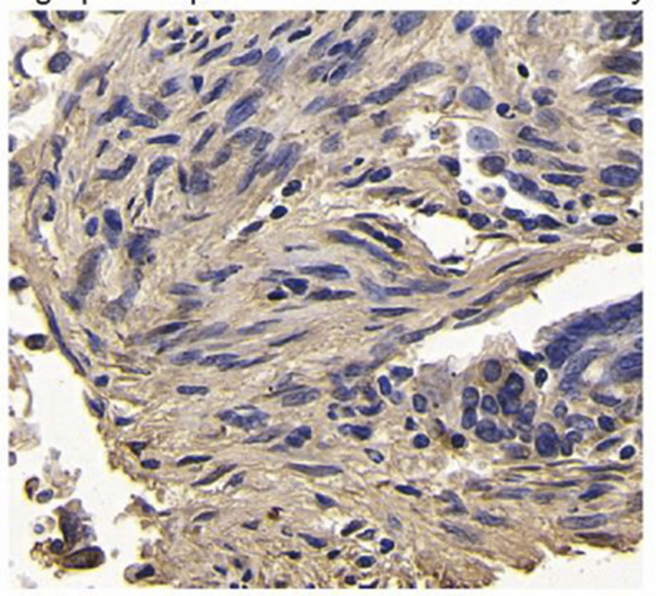

$\mathbf{F}$

pY228-p120-catenin level

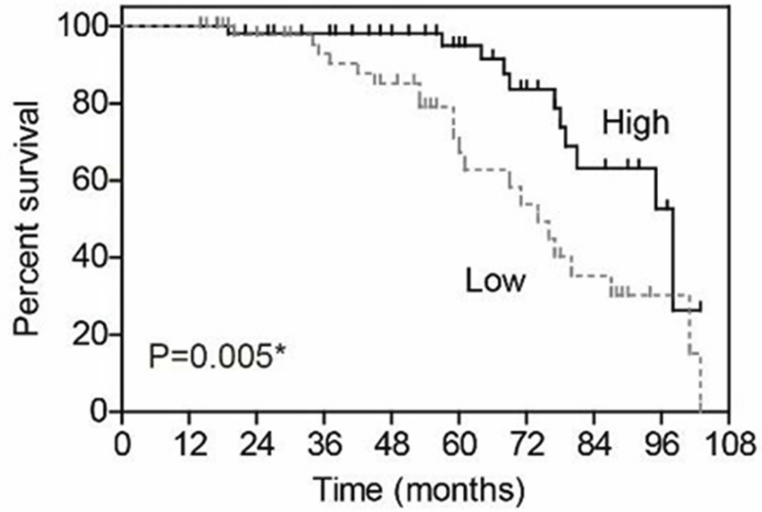

Figure I Expression of pl20-catenin and its phosphorylation on Y228. (A) Representative immunohistochemical result of low pI20-catenin in colon adenocarcinoma (IHC score=I). (B) Representative immunohistochemical result of high pl20-catenin in colon adenocarcinoma (IHC score=4). (C) Representative immunohistochemical result of low pY228-pI20-catenin in colon adenocarcinoma (IHC score=I). (D) Representative immunohistochemical result of high pY228-pI20-catenin in colon adenocarcinoma (IHC score=4). (E) Prognosis curve is plotted by Kaplan-Meier method according to the expression of $\mathrm{p} / 20$-catenin, which shows no statistical significance $(\mathrm{P}=0.559)$. $(\mathbf{F})$ Prognosis curve is plotted by Kaplan-Meier method according to the level of pY228-p/20-catenin, which identifies low phosphorylation level as an unfavorable factor $(\mathrm{P}=0.005)$. IHC images are presented at $100 \mathrm{X}$ magnification. * indicates $\mathrm{P}<0.05$ by log-rank test. 
Table 2 Correlations Between pY228-PI20-Catenin Level And Clinicopathological Characteristics

\begin{tabular}{|c|c|c|c|c|}
\hline \multirow[t]{2}{*}{ Variables } & \multirow{2}{*}{$\begin{array}{l}\text { Patients } \\
(n=104)\end{array}$} & \multicolumn{2}{|c|}{ pl20-Catenin } & \multirow[t]{2}{*}{ P Value } \\
\hline & & $\begin{array}{l}\text { High } \\
(n=56)\end{array}$ & $\begin{array}{l}\text { Low } \\
(n=48)\end{array}$ & \\
\hline $\begin{array}{l}\text { Age (years) } \\
\quad \leq 55 \\
>55\end{array}$ & $\begin{array}{l}49 \\
55\end{array}$ & $\begin{array}{l}29 \\
25\end{array}$ & 20 & 0.162 \\
\hline $\begin{array}{c}\text { Gender } \\
\text { Female } \\
\text { Male }\end{array}$ & $\begin{array}{l}29 \\
75\end{array}$ & $\begin{array}{l}14 \\
40\end{array}$ & 15 & 0.643 \\
\hline $\begin{array}{l}\text { Location } \\
\text { Ascending } \\
\text { Transverse } \\
\text { Descending/ } \\
\text { sigmoid }\end{array}$ & $\begin{array}{l}42 \\
13 \\
49\end{array}$ & $\begin{array}{l}17 \\
7 \\
30\end{array}$ & 25 & 0.141 \\
\hline $\begin{array}{l}\text { Differentiation } \\
\text { Well } \\
\text { Moderate } \\
\text { Poor }\end{array}$ & $\begin{array}{l}16 \\
80 \\
8\end{array}$ & $\begin{array}{l}9 \\
42 \\
3\end{array}$ & 7 & 0.671 \\
\hline $\begin{array}{l}\text { Tumor size } \\
\text { (diameter, cm) } \\
\quad \leq 5.0 \\
>5.0\end{array}$ & $\begin{array}{l}58 \\
46\end{array}$ & $\begin{array}{l}36 \\
18\end{array}$ & 22 & $0.020^{*}$ \\
\hline $\begin{array}{l}\text { Invasion depth } \\
\text { TI-T2 } \\
\text { T3-T4 }\end{array}$ & $\begin{array}{l}47 \\
57\end{array}$ & $\begin{array}{l}32 \\
22\end{array}$ & 15 & $0.003^{*}$ \\
\hline $\begin{array}{l}\text { TNM stage } \\
\quad \text { I-II } \\
\text { III-IV }\end{array}$ & $\begin{array}{l}50 \\
54\end{array}$ & $\begin{array}{l}31 \\
23\end{array}$ & 19 & $0.048^{*}$ \\
\hline
\end{tabular}

Note: *Indicates statistically significant $(\mathrm{P}<0.05)$.

analyses (Figure 2). Among the retrieved features, patients' age, tumor location, tumor differentiation, invasion depth, and TNM stages were all correlated with the clinical prognosis (Table 3). Patients with larger tumor size also showed a poorer overall survival, although the difference was not statistically significant $(\mathrm{P}=0.057)$.

To better evaluate the role of pY228-p120-catenin in predicting CAC prognosis, we put all the factors with $\mathrm{P}<0.10$ in Table 3 into a multivariate Cox regression model. According to the hazard regression, poor tumor differentiation and advanced tumor stages were confirmed as independent prognostic factors (both $\mathrm{P}<0.001$, Table 4). Moreover, the lower pY228-p120-catenin level also showed independent significance in predicting a poorer overall survival $(\mathrm{HR}=2.684,95 \% \quad \mathrm{CI}$ 1.088-6.621,
$\mathrm{P}=0.032$ ). Therefore, clinical data analyses demonstrated a possible antitumor effect of p120-catenin, especially its phosphorylation on Y228, in repressing CAC progression.

\section{PI20-Catenin Suppresses CAC Cell Proliferation And Invasion Via Inhibiting RhoA Signaling}

Cellular experiments were conducted to analyze the detailed function of p120-catenin in CAC by using SW480 cell model. Overexpressing p120-catenin significantly inhibited the proliferation rate of SW480 cells compared to those transfected with pcDNA3.1 vector (Figure 3A). Moreover, the invasion capacity was also impaired by p120-catenin (Figure 3B). We therefore tested several well-known tumor progression downstream biomarkers to explore its underlying mechanisms. Western blot assay showed that p120-catenin inhibit the protein expression of snail and c-myc, while increased the E-cadherin level (Figure 3C and D). The mRNA levels were also tested by using RT-qPCR strategy, which showed a decreased transcription of snail and c-myc. However, the mRNA level of E-cadherin was not affected by overexpressing p120-catenin, indicating a different crosstalk mechanism (Figure 3E).

Of note, immunoprecipitation assay identified the interaction between $\mathrm{p} 120$-catenin and RhoA proteins (Figure 3F). Interestingly, the immunoprecipitated RhoA showed tiny immunoreactivity towards GTP-RhoA, the active form, implying that the binding between p120catenin and RhoA may inhibit the activation of RhoA. Consistently, the activation of RhoA and its downstream ROCK1 was inhibited by overexpressing p120-catenin without affecting total RhoA protein expression (Figure 3F).

\section{Phosphorylation Of Y228 Enhances The Tumor Suppressive Effects Of PI20- Catenin}

We also explored the significance of Y228 on the antitumor effects of $\mathrm{p} 120$-catenin by generating phosphor-mimic mutant Y228E and phosphor-deficient mutant Y228F. Proliferation assay revealed that Y228E showed more potent effect on suppressing SW480 cell proliferation, while $\mathrm{Y} 228 \mathrm{~F}$ mutant showed poorer anti-proliferation effect (Figure 4A). Similarly, Matrigel-transwell experiments identified the most significant anti-invasion effect of Y228E mutant (Figure 4B). 
A

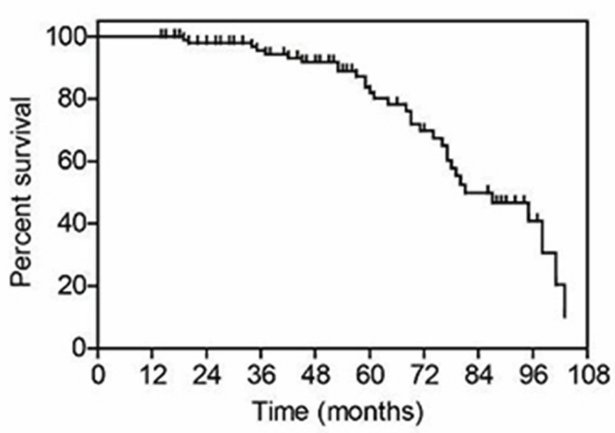

C

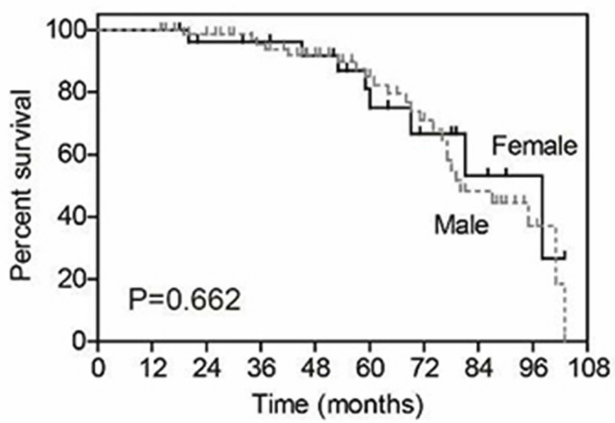

E

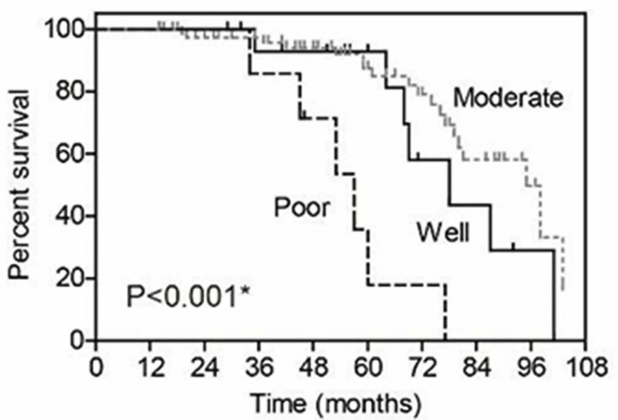

G

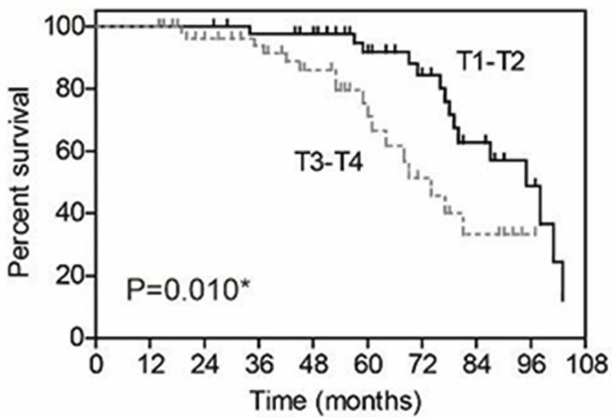

B

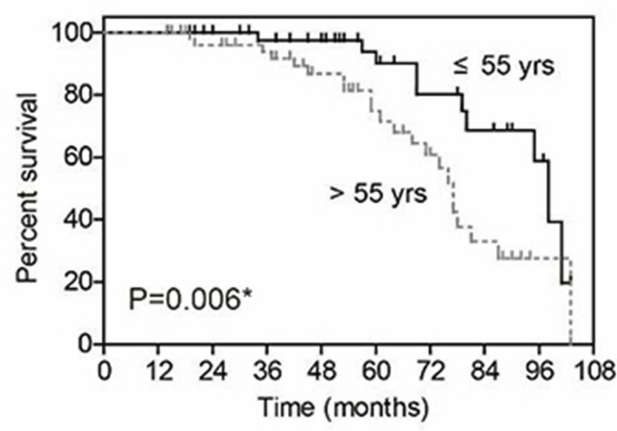

D

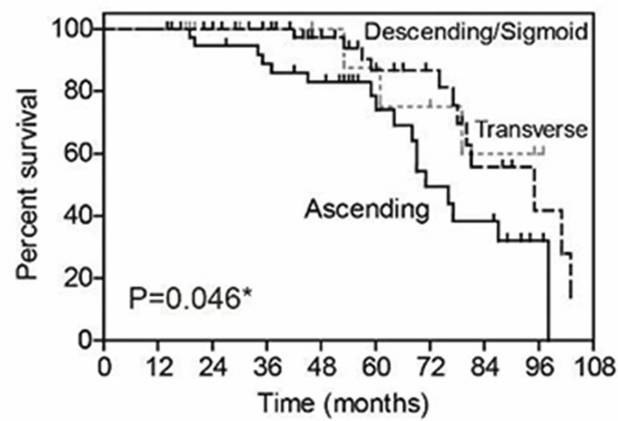

F

Tumor size (diameter)

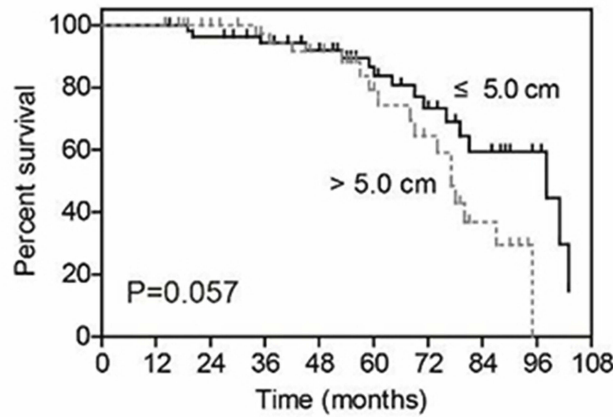

H

TNM stage

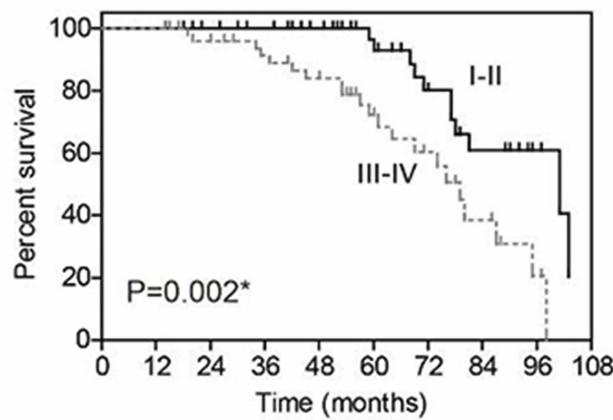

Figure 2 Overall survival analyses of colon adenocarcinoma patients. The overall survival of entire cohort is shown in (A), the 5 -year overall survival rate is $82.0 \%$. The effect of each clinicopathological parameter on patients' survival is tested by Kaplan-Meier and log-rank test, including age (B), gender (C), tumor location (D), tumor differentiation $(\mathbf{E})$, tumor size $(\mathbf{F})$, tumor invasion depth $(\mathbf{G})$, and TNM stage $(\mathbf{H})$. 
Table 3 Kaplan-Meier Survival Analyses And log rank tests

\begin{tabular}{|c|c|c|c|c|}
\hline \multirow[t]{2}{*}{ Variable } & Cases & $\begin{array}{l}\text { Survival } \\
\text { Months }\end{array}$ & $\begin{array}{l}5 \text {-Year } \\
\text { OS }\end{array}$ & \multirow[t]{2}{*}{ P Value } \\
\hline & (n) & $\begin{array}{l}\text { (Mean } \pm \\
\text { S.D.) }\end{array}$ & (\%) & \\
\hline \multicolumn{5}{|l|}{ Age (years) } \\
\hline$\leq 55$ & 49 & $89.7 \pm 3.4$ & $90.2 \%$ & $0.006^{*}$ \\
\hline$>55$ & 55 & $75.0 \pm 4.0$ & $74.8 \%$ & \\
\hline \multicolumn{5}{|l|}{ Gender } \\
\hline Female & 29 & $82.5 \pm 5.5$ & $74.9 \%$ & 0.662 \\
\hline Male & 75 & $81.7 \pm 3.2$ & $85.0 \%$ & \\
\hline \multicolumn{5}{|l|}{ Location } \\
\hline Ascending & 42 & $72.9 \pm 4.5$ & $74.0 \%$ & $0.046^{*}$ \\
\hline Transverse & 13 & $84.3 \pm 6.1$ & $87.5 \%$ & \\
\hline $\begin{array}{l}\text { Descending/ } \\
\text { sigmoid }\end{array}$ & 49 & $87.3 \pm 3.8$ & $86.6 \%$ & \\
\hline \multicolumn{5}{|l|}{ Differentiation } \\
\hline Well & 16 & $79.1 \pm 6.3$ & $92.9 \%$ & $<0.001 *$ \\
\hline Moderate & 80 & $85.9 \pm 3.2$ & $87.4 \%$ & \\
\hline Poor & 8 & $55.4 \pm 5.6$ & $17.9 \%$ & \\
\hline \multicolumn{5}{|l|}{$\begin{array}{l}\text { Tumor size } \\
\text { (diameter, cm) }\end{array}$} \\
\hline$\leq 5.0$ & 58 & $85.4 \pm 3.8$ & $83.8 \%$ & 0.057 \\
\hline$>5.0$ & 46 & $75.7 \pm 3.6$ & $79.3 \%$ & \\
\hline \multicolumn{5}{|l|}{ Invasion depth } \\
\hline TI-T2 & 47 & $88.4 \pm 3.1$ & $91.7 \%$ & $0.010 *$ \\
\hline T3-T4 & 57 & $72.5 \pm 4.0$ & $71.2 \%$ & \\
\hline \multicolumn{5}{|l|}{ TNM stage } \\
\hline I-II & 50 & $90.5 \pm 3.4$ & $92.9 \%$ & $0.002^{*}$ \\
\hline III-IV & 54 & $73.2 \pm 3.9$ & $72.2 \%$ & \\
\hline \multicolumn{5}{|l|}{ pl20-catenin } \\
\hline High & 56 & $83.8 \pm 4.2$ & $80.2 \%$ & 0.559 \\
\hline Low & 48 & $80.6 \pm 3.6$ & $84.1 \%$ & \\
\hline \multicolumn{5}{|l|}{ pY228-p I 20-catenin } \\
\hline High & 54 & $88.8 \pm 3.2$ & $95.0 \%$ & $0.005^{*}$ \\
\hline Low & 50 & $74.0 \pm 4.3$ & $67.2 \%$ & \\
\hline
\end{tabular}

Note: *Indicates statistically significant $(P<0.05)$.

Consistent with the proliferation and invasion results, quantitative PCR showed the same prevalence of alterations on snail and c-myc levels (Figure 4C). Comparing with wild type (WT) p120-catenin, Y228E inhibited those oncogenic protein expressions while $\mathrm{Y} 228 \mathrm{~F}$ enhanced their expressions (Figure 4D). Moreover, interaction between p120-catenin and RhoA was most tightly in Y228E group, whereas impaired in Y228F group. The E-cadherin level was increased by transfecting Y228E
Table 4 Multivariate Analysis For Independent Predictive Factors Of CAC Patients

\begin{tabular}{|c|c|c|c|}
\hline Variable & HR & $95 \% \mathrm{Cl}$ & P Value \\
\hline \multicolumn{4}{|l|}{ Age (years) } \\
\hline$\leq 55$ & Reference & & \\
\hline$>55$ & 2.318 & $0.988-5.436$ & 0.053 \\
\hline \multicolumn{4}{|l|}{ Location } \\
\hline Ascending/transverse & Reference & & \\
\hline Descending/sigmoid & 0.787 & $0.532-1.164$ & 0.230 \\
\hline \multicolumn{4}{|l|}{ Differentiation } \\
\hline Well/moderate & Reference & & \\
\hline Poor & 9.993 & $3.320-30.081$ & $<0.00 I^{*}$ \\
\hline \multicolumn{4}{|l|}{$\begin{array}{l}\text { Tumor size (diameter, } \\
\mathrm{cm} \text { ) }\end{array}$} \\
\hline$\leq 5.0$ & Reference & & \\
\hline$>5.0$ & 1.708 & $0.775-3.763$ & 0.184 \\
\hline \multicolumn{4}{|l|}{ Invasion depth } \\
\hline $\mathrm{TI}-\mathrm{T} 2$ & Reference & & \\
\hline T3-T4 & 1.457 & $0.62 I-3.4 I 7$ & 0.387 \\
\hline \multicolumn{4}{|l|}{ TNM stage } \\
\hline I-II & Reference & & \\
\hline III-IV & 4.998 & $2.051-12.182$ & $<0.00 I^{*}$ \\
\hline \multicolumn{4}{|l|}{ pY228-pI 20-catenin } \\
\hline High & Reference & & \\
\hline Low & 2.684 & $|.088-6.62|$ & $0.032 *$ \\
\hline
\end{tabular}

Note: *Indicates statistically significant $(P<0.05)$.

and decreased by transfecting Y228F, indicating that phosphorylation of p120-catenin on Y228 may help maintain E-cadherin protein stability. On the other hand, overexpressing Y228E-p120-catenin further attenuated the activation of RhoA, thus exhibiting antitumor effects.

\section{Src Is An Upstream Kinase Of PI20- Catenin Targeting Y228 Site}

There have been studies reporting that Src can phosphorylate p120-catenin on Y228 in glioma cells and RWP-1 cells, ${ }^{22,23}$ we were interested to test whether Src can affect Y228 phosphorylation in CAC. The protein level of Src in clinical tumor tissues was tested by IHC (Figure 5A and B). Relationship between Src and pY228-p120-catenin was analyzed by Chi-square test, which showed a lower pY228 level in the samples with lower Src expression (Figure 5C, $\mathrm{P}=0.003$ ). Additionally, we established p120catenin stable cell line in SW480 cells, then transfected with Src-siRNA or Src-plasmids. The Western blot results revealed a decreased pY228 level in cells silencing Src 
A

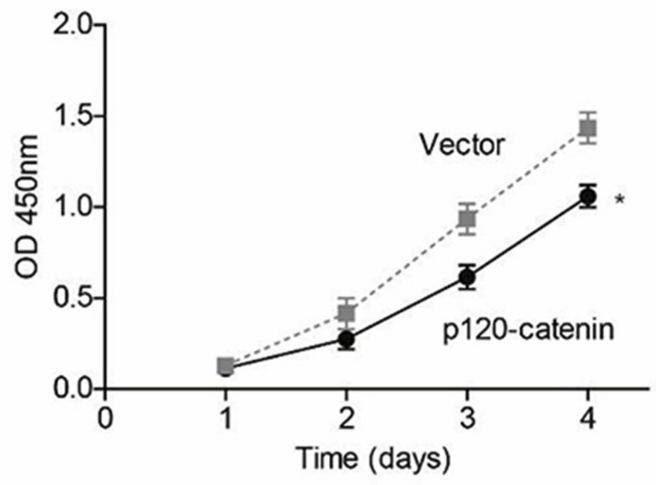

C

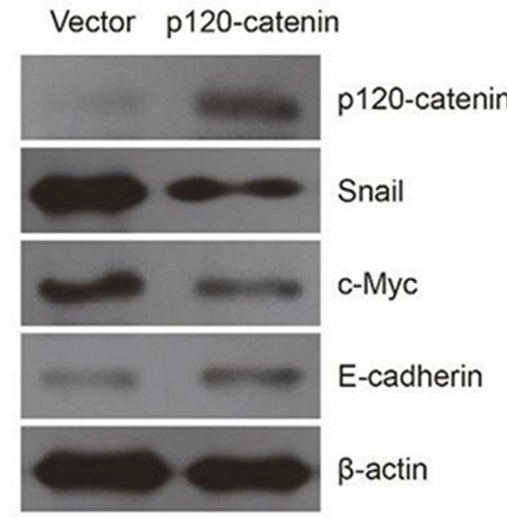

E

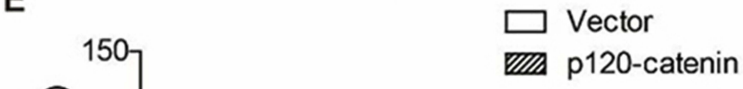

B

D
Matrigel-Transwell assay
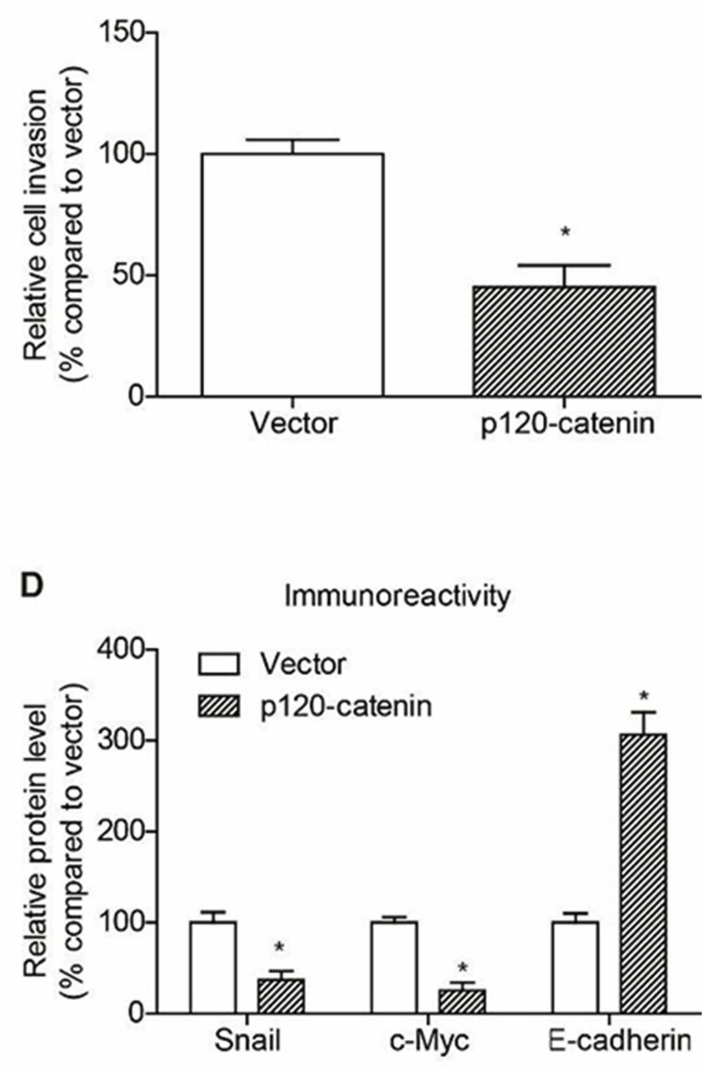

F Vector p120-catenin

IP

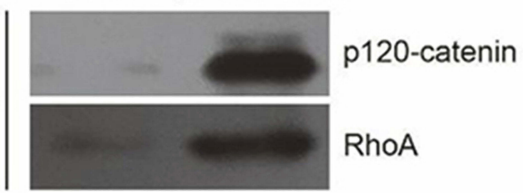

IB

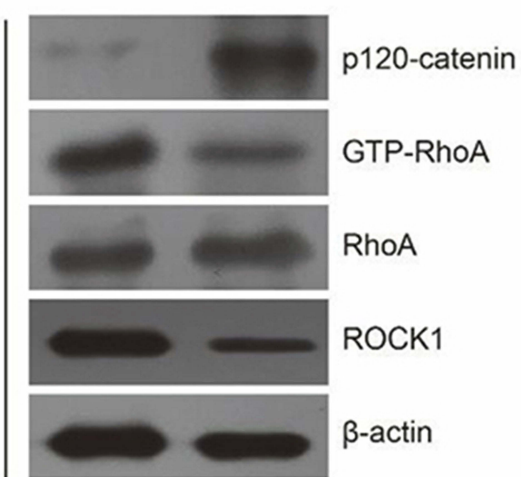

Figure 3 PI20-catenin inhibits proliferation and invasion of SW480 cells. (A) The proliferation process of SW480 cells is evaluated by CCK-8 assay, showing the antiproliferation effect of pI20-catenin. (B) Cells transfected with pcDNA3.I vector or pcDNA3.I-pI20-catenin are subjected to Matrigel-transwell assay to test cell invasion capacity. Accordingly, pl20-catenin inhibits invasion of SW480 cells. (C) Transfection of pl20-catenin plasmids induced decreased expression of snail and c-myc proteins, while increased the E-cadherin level. Immunoblotting data are semi-quantified by Image J software (D). (E) The mRNA level of c-myc and snail is upregulated by pI20catenin. In contrast, the E-cadherin RNA level is not affected by p/20-catenin. (F) Immunoprecipitation assay identified the interaction between pI20-catenin and RhoA. In addition, overexpressing pl20-catenin resulted in decreased level of active RhoA (GTP-RhoA) without affecting the total RhoA protein level. The well-known RhoA downstream protein ROCKI was also inhibited by $\mathrm{p} 120$-catenin transfection. *Indicates $\mathrm{P}<0.05$ by Student's $t$ test. 
A
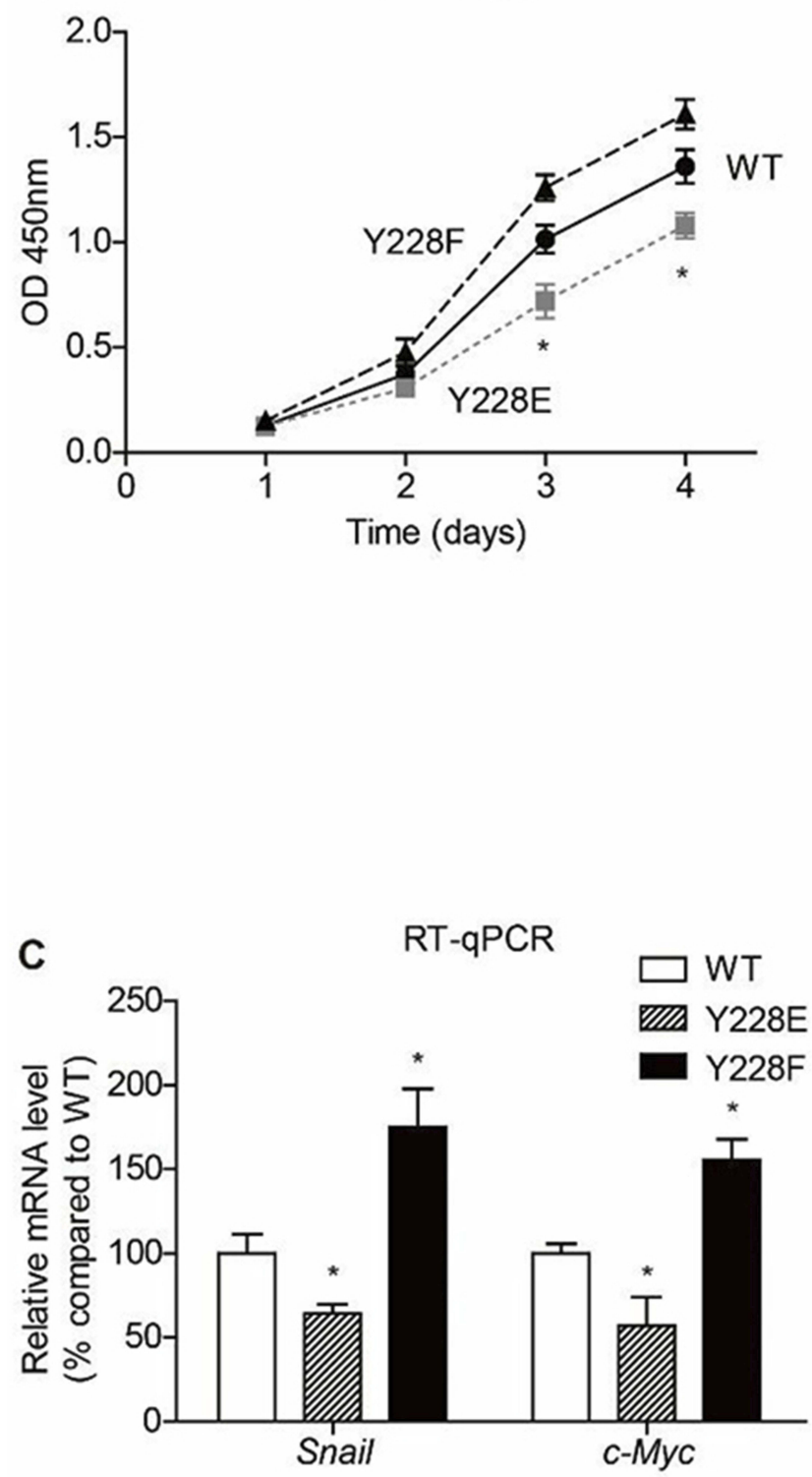

\section{B Matrigel-Transwell assay}

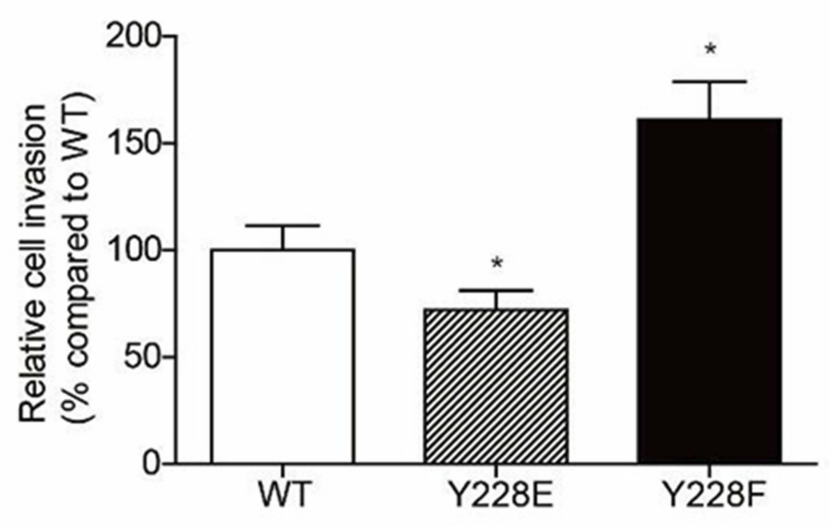

D
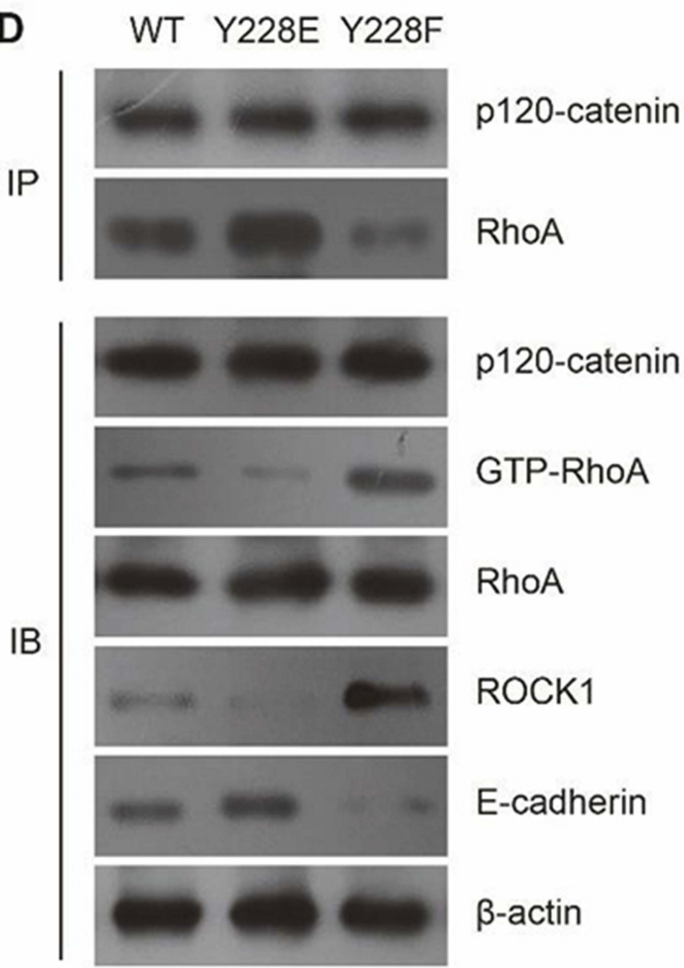

Figure 4 Phosphorylation on Y228 is critical on inhibiting colon cancer progression. Y228 on pl20-catenin was mutated into E (Y228E) to mimic phosphorylated residue and $\mathrm{F}(\mathrm{Y} 228 \mathrm{~F})$ to abolish phosphorylation function. (A) The proliferation process of SW480 cells is evaluated by CCK-8 assay, showing that $\mathrm{Y} 228 \mathrm{~F}$ attenuated the anticancer effect of pl20-catenin. (B) Similarly, Matrigel-transwell results indicated that the invasion capacity was further enhanced after mutating $Y$ into E, compared with wild type (WT) p 120-catenin. (C) Transcription of RhoA downstream effectors, such as snail and c-myc, was further impaired in Y228E while rescued in Y228F, indicating the crucial role of $Y 228$ phosphorylation in suppressing cancer progression. (D) Y228E stabilizes the pl20-catenin-RhoA interaction while $Y 228 \mathrm{~F}$ interrupts this interaction, compared with the wild type. Consistently, the GTP-RhoA and ROCKI levels were lowest in Y228E group. In contrast, the E-cadherin showed a highest level in Y228E transcription group. *Indicates $\mathrm{P}<0.05$ by One-way ANOVA $t$ test.

without affecting total p120-catenin expression. In contrast, overexpressing Src resulted in a higher pY228 level (Figure 5D). Therefore, we proposed our hypothesis that phosphorylation of Y228 on p120-catenin enhanced its interaction with RhoA and inhibited its activation, subsequently inhibit the tumor progression of CAC (Figure 5E).

\section{Discussion}

In the current study, we reported that the phosphorylation on site Y228 of p120-catenin is an independent prognostic factor indicating the better prognosis of CAC patients. Patients with hypophosphorylation level showed unfavorable clinical outcomes compared to those with more 
A Low Src immunoreactivity

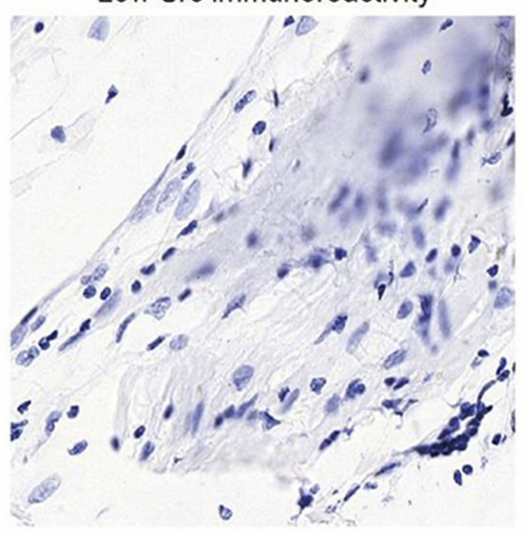

B

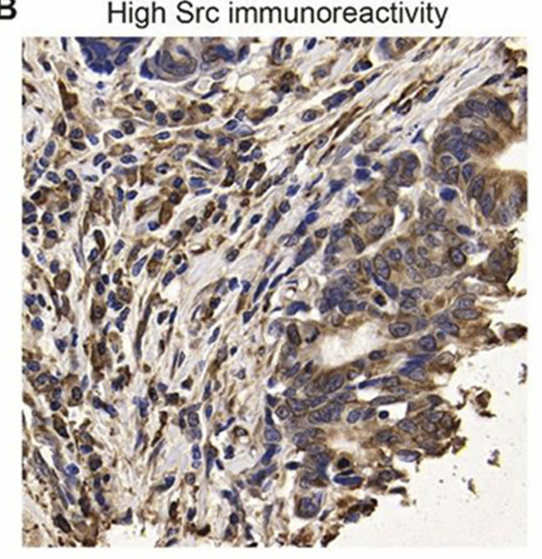

C Correlations between Src and pY228-p120-catenin
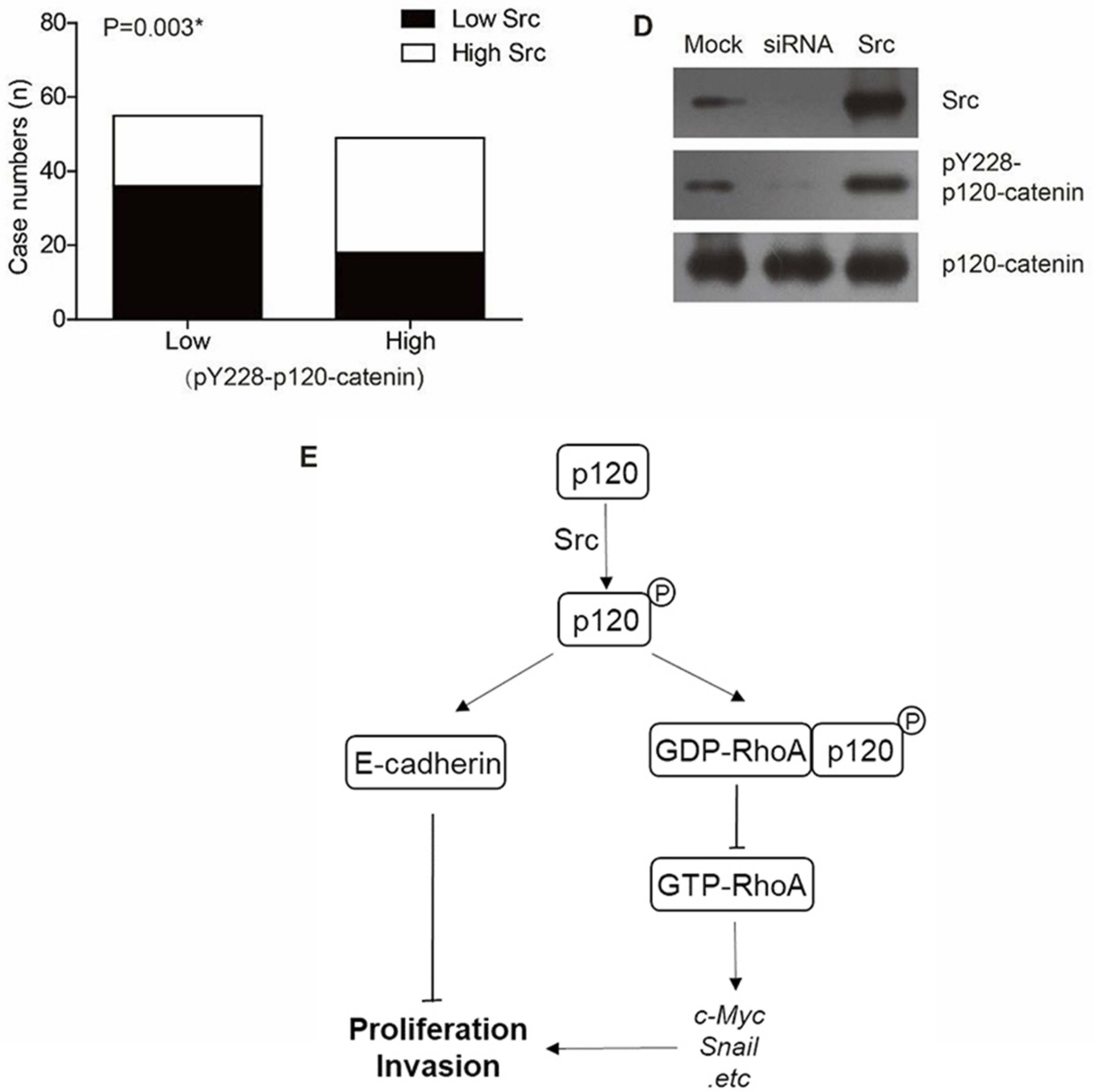

Figure $5 \mathrm{Src}$ is the upstream kinase catalyzing Y228 phosphorylation of pl20-catenin. (A) Representative immunohistochemical result of low Src expression in colon adenocarcinoma (IHC score=I). (B) Representative immunohistochemical result of high Src expression in colon adenocarcinoma (IHC score=4). (C) Higher Src expression is correlated with higher pY228-pI20-catenin level in clinical CAC tissues ( $\mathrm{P}=0.003$ ). (D) Overexpression of Src induced hyperphosphorylation of Y228 on pI20-catenin, while silencing Src by siRNA resulted in a lower pY228-p120-catenin level compared to the control group. (E) A schematic model shows our hypothesis that pI20-catenin exhibits anticancer functions via E-cadherin and RhoA signaling pathways. 
phosphorylated p120-catenin. Although the total protein expression of p120-catenin showed no significant effect on overall survival of our cohort, its lower expression was correlated with advanced TNM stages, indicating a possibility of p120-catenin to exert a tumor-suppressive role in CAC. Therefore, we performed a series of following experiments to verify whether p120-catenin could inhibit proliferation, invasion and EMT in CAC cells, and tested the underlying mechanisms of how p120-catenin and its phosphorylation regulate the malignant behaviors in vitro.

Accumulating evidence showed that tumor metastasis is one of the most important features indicating unfavorable prognosis. ${ }^{22,24}$ Tumor cell metastasis is characterized by decreased cell-cell adhesion and epithelial-mesenchymal transition. E-cadherin is a key suppressor of EMT, a key process for tumor cells to acquire the capability of invasion and migration. The $\mathrm{p} 120$-catenin protein has been shown to interact with the cytoplasmic domain of E-cadherin, which helps stabilizing E-cadherin and enhancing cell-cell adhesion. ${ }^{25}$ Therefore, dysregulation or decreased expression of p120-catenin is likely to associate to the tumor cell metastasis. In the present study, the protein level of E-cadherin was upregulated in CAC cells transfected with p120-catenin, however, the mRNA level shows no significant alteration. The different pattern between mRNA and protein levels is consistent with previous studies on the effects of p120-catenin on regulating E-cadherin ${ }^{26}$ Together, it could be indicated that p120catenin may exert an inhibitory effect on EMT in CAC by stabilizing E-cadherin.

Besides E-cadherin, our data also indicated that p120catenin could interact with GDP-binded RhoA, subsequently attenuate GDP-GTP exchange on RhoA. Consistently, overexpression of p120-catenin downregulated GTP-RhoA without affecting the total RhoA protein expression. Moreover, the downstream effector of RhoA signaling, such as c-myc and snail ${ }^{27}$ were downregulated by p120-catenin transfection. Additionally, by introducing phosphor-mimic and phosphor-deficient mutagenesis, we verified that phosphorylation of Y228 enhances this signaling pathway through stabilizing the p120-catenin-RhoA interaction. The Src kinase has been reported to phosphorylate Y228 of p120-catenin in several cell types. ${ }^{14,28,29}$ Our results expanded on this kinase-substrate relationship in colon adenocarcinoma SW480 cells, thus evidenced that Src may be one of the upstream kinase of p120 which phosphorylates its Y228 tyrosine, and thus regulate its downstream signaling axis.
There are several limitations of this study. Firstly, the clinical data were collected from only one hospital and cannot avoid regional bias, cooperation between multiple medical centers will help validate our conclusions. Secondly, in vivo experiments using mice models will be invaluable to further verify the effects of p120-catenin and its phosphorylation in CAC. Thirdly, the Src protein is recognized as an oncogenic protein in many cancer types however shows tumor-suppressive potency by phosphorylating p120-catenin according to our results. Therefore, a more systematic study on Src's effects in colon adenocarcinoma is essential to better elucidate its tumor-related roles.

\section{Conclusion}

P120-catenin and its phosphorylation on site Y228 play antiproliferation and EMT-suppressive effects in colon adenocarcinoma cells, which is at least partly established via inhibiting RhoA activation and stabilizing E-cadherin. Hypophosphorylation of Y228 on p120-catenin in tumor tissues is associated with poor clinical outcomes of colon adenocarcinoma patients.

\section{Ethics Statement}

This study was conducted in accordance with the Declaration of Helsinki and approved by the Ethics Committee of Linyi Central Hospital. Furthermore, our study was obtained from each patient or direct relatives.

\section{Disclosure}

The authors report no conflicts of interest in this work.

\section{References}

1. Bray F, Ferlay J, Soerjomataram I, Siegel RL, Torre LA, Jemal A. Global cancer statistics 2018: GLOBOCAN estimates of incidence and mortality worldwide for 36 cancers in 185 countries. CA Cancer J Clin. 2018;68(6):394-424. doi:10.3322/caac.v68.6

2. Sung JJ, Lau JY, Goh KL, Leung WK; Asia Pacific Working Group on Colorectal C. Increasing incidence of colorectal cancer in Asia: implications for screening. Lancet Oncol. 2005;6(11):871-876. doi:10.1016/S1470-2045(05)70422-8

3. Chua YJ, Zalcberg JR. Progress and challenges in the adjuvant treatment of stage II and III colon cancers. Expert Rev Anticancer Ther. 2008;8(4):595-604. doi:10.1586/14737140.8.4.595

4. He G, Zou L, Zhou L, Gao P, Qian X, Cui J. Cysteine-rich intestinal protein 1 silencing inhibits migration and invasion in human colorectal cancer. Cell Physiol Biochem. 2017;44(3):897-906. doi:10.11 $59 / 000485357$

5. Liu H, Xu Y, Zhang Q, et al. Prognostic significance of TBL1XR1 in predicting liver metastasis for early stage colorectal cancer. Surg Oncol. 2017;26(1):13-20. doi:10.1016/j.suronc.2016.12.003 
6. Ba S, Xuan Y, Long ZW, Chen HY, Zheng SS. MicroRNA-27a promotes the proliferation and invasiveness of colon cancer cells by targeting SFRP1 through the Wnt/beta-catenin signaling pathway. Cell Physiol Biochem. 2017;42(5):1920-1933. doi:10.1159/000479610

7. Liu H, Xu Y, Zhang Q, et al. Correlations between TBL1XR1 and recurrence of colorectal cancer. Sci Rep. 2017;7:44275. doi:10.1038/ srep44275

8. Nelson WJ, Nusse R. Convergence of Wnt, beta-catenin, and cadherin pathways. Science. 2004;303(5663):1483-1487. doi:10.1126/ science. 1094291

9. Xu Y, Yang X, Li Z, et al. Sprouty2 correlates with favorable prognosis of gastric adenocarcinoma via suppressing FGFR2-induced ERK phosphorylation and cancer progression. Oncotarget. 2017;8 (3):4888-4900. doi:10.18632/oncotarget.13982

10. Hou S, Du P, Wang P, Wang C, Liu P, Liu H. Significance of MNK1 in prognostic prediction and chemotherapy development of epithelial ovarian cancer. Clin Transl Oncol. 2017;19(9):1107-1116. doi:10. 1007/s12094-017-1646-x

11. Ireton RC, Davis MA, van Hengel J, et al. A novel role for p120 catenin in E-cadherin function. $J$ Cell Biol. 2002;159(3):465-476. doi:10.1083/jcb.200205115

12. Ishiyama N, Lee SH, Liu S, et al. Dynamic and static interactions between p120 catenin and E-cadherin regulate the stability of cell-cell adhesion. Cell. 2010;141(1):117-128. doi:10.1016/j.cell.2010.01.017

13. Reynolds AB, Roczniak-Ferguson A. Emerging roles for p120-catenin in cell adhesion and cancer. Oncogene. 2004;23(48):7947-7956. doi:10.1038/sj.onc.1208161

14. Anastasiadis PZ, Reynolds AB. The p120 catenin family: complex roles in adhesion, signaling and cancer. $J$ Cell Sci. 2000;113(Pt 8):1319-1334.

15. Schackmann RC, Tenhagen M, van de Ven RA, Derksen PW. p120catenin in cancer - mechanisms, models and opportunities for intervention. J Cell Sci. 2013;126(Pt 16):3515-3525. doi:10.1242/jcs.134411

16. Shrestha N, Shrestha H, Ryu T, et al. Delta-catenin increases the stability of EGFR by decreasing c-Cbl interaction and enhances EGFR/Erk1/2 signaling in prostate cancer. Mol Cells. 2018;41 (4):320-330. doi:10.14348/molcells.2018.2292

17. Yang CT, Li JM, Chu WK, Chow SE. Downregulation of lumican accelerates lung cancer cell invasion through p120 catenin. Cell Death Dis. 2018;9(4):414. doi:10.1038/s41419-017-0212-3

18. Hendley AM, Wang YJ, Polireddy K, et al. p120 catenin suppresses basal epithelial cell extrusion in invasive pancreatic neoplasia. Cancer Res. 2016;76(11):3351-3363. doi:10.1158/0008-5472.CAN$15-2268$
19. Lehman HL, Kidacki M, Warrick JI, Stairs DB. NFkB hyperactivation causes invasion of esophageal squamous cell carcinoma with EGFR overexpression and p120-catenin down-regulation. Oncotarget. 2018;9(13):11180-11196. doi:10.18632/oncotarget.v9i13

20. Johnson E, Seachrist DD, DeLeon-Rodriguez CM, et al. HER2/ ErbB2-induced breast cancer cell migration and invasion require p120 catenin activation of Rac1 and Cdc42. J Biol Chem. 2010;285 (38):29491-29501. doi:10.1074/jbc.M110.136770

21. Pham TND, Perez White BE, Zhao H, Mortazavi F, Tonetti DA. Protein kinase $\mathrm{C}$ alpha enhances migration of breast cancer cells through FOXC2-mediated repression of p120-catenin. BMC Cancer. 2017;17(1):832. doi:10.1186/s12885-017-3827-y

22. Tokunaga T, Oshika Y, Abe Y, et al. Vascular endothelial growth factor (VEGF) mRNA isoform expression pattern is correlated with liver metastasis and poor prognosis in colon cancer. $\mathrm{Br} J$ Cancer. 1998;77(6):998-1002. doi:10.1038/bjc.1998.164

23. Castano J, Solanas G, Casagolda D, et al. Specific phosphorylation of p120-catenin regulatory domain differently modulates its binding to RhoA. Mol Cell Biol. 2007;27(5):1745-1757. doi:10.1128/ MCB.01974-06

24. Tsujii M, Kawano S, DuBois RN. Cyclooxygenase-2 expression in human colon cancer cells increases metastatic potential. Proc Natl Acad Sci U S A. 1997;94(7):3336-3340. doi:10.1073/pnas.94.7.3336

25. Davis MA, Ireton RC, Reynolds AB. A core function for p120catenin in cadherin turnover. $J$ Cell Biol. 2003;163(3):525-534. doi: $10.1083 /$ jcb.200307111

26. Kourtidis A, Ngok SP, Anastasiadis PZ. p120 catenin: an essential regulator of cadherin stability, adhesion-induced signaling, and cancer progression. Prog Mol Biol Transl Sci. 2013;116:409-432.

27. Sauzeau V, Berenjeno IM, Citterio C, Bustelo XR. A transcriptional cross-talk between RhoA and c-Myc inhibits the RhoA/Rock-dependent cytoskeleton. Oncogene. 2010;29(26):3781-3792. doi:10.1038/ onc. 2010.134

28. Mariner DJ, Anastasiadis P, Keilhack H, Bohmer FD, Wang J, Reynolds AB. Identification of Src phosphorylation sites in the catenin p120ctn. J Biol Chem. 2001;276(30):28006-28013. doi:10.1074/ jbc.M102443200

29. Schaberg KE, Shirure VS, Worley EA, George SC, Naegle KM. Ensemble clustering of phosphoproteomic data identifies differences in protein interactions and cell-cell junction integrity of HER2-overexpressing cells. Integr Biol (Camb). 2017;9(6):539-547. doi:10.1039/C7IB00054E
OncoTargets and Therapy

\section{Publish your work in this journal}

OncoTargets and Therapy is an international, peer-reviewed, open access journal focusing on the pathological basis of all cancers, potential targets for therapy and treatment protocols employed to improve the management of cancer patients. The journal also focuses on the impact of management programs and new therapeutic

Submit your manuscript here: https://www.dovepress.com/oncotargets-and-therapy-journa agents and protocols on patient perspectives such as quality of life, adherence and satisfaction. The manuscript management system is completely online and includes a very quick and fair peer-review system, which is all easy to use. Visit http://www.dovepress.com/ testimonials.php to read real quotes from published authors. 